\title{
Early interventions for the prevention of PTSD in adults: a systematic literature review
}

\author{
Ila M. P. Linares'1, Felipe D’Alessandro F. Corchs², Marcos Hortes N. Chagas³ ${ }^{3}$ Antonio Waldo Zuardi' 1 , \\ Rocio Martin-Santos ${ }^{4}$, José Alexandre S. Crippa ${ }^{1}$
}

\author{
' Department of Neuroscience and Behavior, Ribeirão Preto Medical School, University of São Paulo (FMRP-USP), and National Institute for Translational Medicine (INCT, CNPq), Ribeirão Preto, \\ SP, Brazil. \\ 2 Núcleo Paradigma de Análise do Comportamento, Department of Psychiatry, University of São Paulo Medical School (FMUSP), São Paulo, SP, Brazil. \\ ${ }^{3}$ Centro de Ciências Biológicas e da Saúde, Departamento de Gerontologia, Universidade Federal de São Carlos (UFSCar), São Carlos, SP, Brazil. \\ ${ }^{4}$ Department of Psychiatry, Institute of Neurosciences, Hospital Clınic, IDIBAPS, CIBERSAM, Barcelona, Spain.
}

Received: 8/24/2016 - Accepted: $11 / 28 / 2016$

DOl: 10.1590/0101-60830000000109

\begin{abstract}
Background: Secondary interventions are implemented within a short interval following the occurrence of traumatic events with the purpose of preventing the onset of PTSD. Objective: Analyze the results of studies that assessed post-trauma interventions in adults aimed at preventing the onset of PTSD or symptoms related to PTSD. Methods: We performed literature searches using the search expression [(Early intervention OR secondary prevention) AND (Post traumatic stress disorder OR PTSD)] for articles published until October 2016. Among the references found, 29 fulfilled the selection criteria established for the review. Data were divided and analyzed according to the type of intervention: pharmacological or psychological. Results: Psychological measures used in the studies lack homogeneity regarding the type of intervention and the assessment of intervention outcomes. Pharmacological interventions were less frequent and findings require replication, together with an expansion in the types of substances investigated. In general, many of the studies reviewed suggest that both pharmacological and psychological interventions are effective in the prevention of PTSD. Discussion: Future trials should be focused on determining the best interventions for the secondary prevention of PTSD. The combination of psychological and pharmacological interventions for post-trauma patients poses opportunities and challenges that remain unexplored.
\end{abstract}

Linares IMP et al. / Arch Clin Psychiatry. 2017;44(1):23-9

Keywords: Early intervention, post-traumatic stress disorder, literature review.

\section{Introduction}

According to the DSM-IV, post-traumatic stress disorder (PTSD) is characterized by a set of responses triggered by exposure to a significant traumatic event. The condition generally involves four groups of symptoms consisting of persistent re-experiencing of the traumatic event in one or more forms (e.g., in nightmares or through feelings similar to those experienced in the traumatic event), constant avoidance of stimuli associated with the trauma, recurrent arousal responses, and cognition or mood alterations associated with the traumatic event. These symptoms should last more than a month and be followed by significant impairment or distress for the individual ${ }^{1}$.

Interventions implemented shortly after the occurrence of the trauma are aimed at the secondary prevention of PTSD, that is, they are attempts to avoid the development of the disorder in individuals who have already been exposed to the traumatic event and reduce occasional harms resulting from the experience. Secondary interventions have received increasing attention because of the high prevalence of PTSD in the population $6.8 \%$ in the American population according to Kessler ${ }^{2}$ and the protective action of posttrauma interventions ${ }^{3}$. In addition, the World Health Organization has listed important impacts of PTSD: economical and on social, interpersonal, and occupational functioning, adding that prevention strategies should be broadly promoted ${ }^{4}$.

In this article, we present the results of a systematic literature review on post-trauma interventions for adults aimed at preventing the onset of PTSD or symptoms related to the disorder. We were unable to use a quantitative approach such as a meta-analysis because (a) the information required for the calculation of effect sizes was not always available, which could restrict the analysis to a small subset of studies; (b) there were important differences regarding secondary variables in the studies (e.g., gender, type of trauma, medication, comorbid conditions); (c) different methods were used to analyze data obtained through different forms of investigation; and (d) meta-analysis have intrinsic limitations related to the estimates of unpublished negative results (the "file drawer problem"5). The review was also limited to studies involving adult participants, since current models show that the development of PTSD in children is different from that of adults in terms of biological, psychological, and social aspects and the interactions between them ${ }^{6}$.

\section{Methods}

We made a search using the search expression [(Early intervention OR secondary prevention) AND (Post traumatic stress disorder OR $P T S D)]$ on the electronic databases MEDLINE, Web of Knowledge, SciELO, PsycINFO, and LILACS. Articles published until October 2016 were included, with no previous time limit. The reference lists of the selected articles were manually checked for additional references relevant to the topic of the review.

The articles included in the review were published in English, Spanish or Portuguese. We included studies involving humans aged 18 or above who had suffered any type of trauma and which presented results of interventions effected up to one month after the traumatic event (this criterion was based on DSM-5, where PTSD is characterized by disturbances lasting more than one month after the trauma). In respect to the type of intervention, we included articles that assessed the effects of pharmacological or psychological trials.

Review articles, letters to the editor, editorials, abstracts published in the annals of scientific events, case reports, and articles dealing with other disorders different from PTSD or its prevention were not included in this review. 
The electronic searches returned 22 articles that fulfilled the inclusion criteria for the review. Seven additional articles were included after hand-search of the reference lists of those articles. Figure 1 illustrates the process of article search, selection, and exclusion.

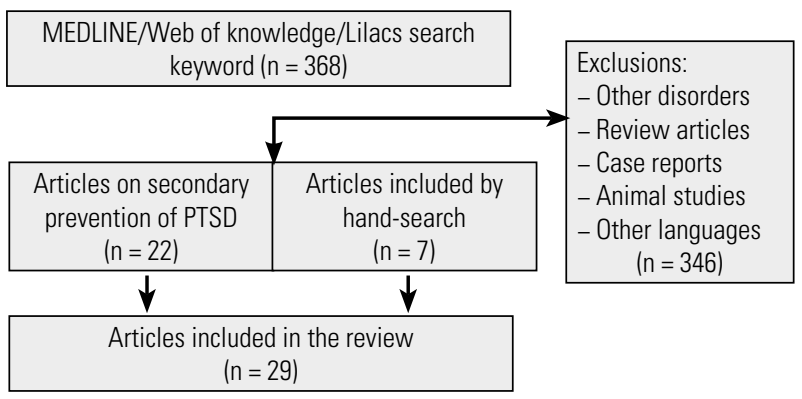

Figure 1. Flowchart showing the process of search and selection of articles included in the review.

\section{Results and discussion}

Table 1 presents the clinical and demographic data of the participants included in the 29 articles reviewed, whereas Table 2 describes the methodological aspects of the studies. Results were divided according to the type of intervention (pharmacological or psychological). From the 29 articles reviewed, 16 reported significant effects of interventions for the prevention of PTSD or symptoms related to the disorder ${ }^{7-22}$. Of these, 22 studies used psychological interventions and 7 used pharmacological interventions (Table 2).

\section{Psychological interventions}

We considered as psychological interventions those approaches that were not based on the administration of pharmacological substances. The main psychological approaches used in the studies were cognitive behavioral therapy (CBT) and debriefing, followed by other approaches described below.

Table 1. Clinical and demographic data of samples included in the studies reviewed

\begin{tabular}{|c|c|c|c|c|c|}
\hline Reference & Subjects & $\mathrm{N}(\mathrm{M} / \mathrm{F})$ & $\begin{array}{l}\text { Mean age } \pm S D \\
\text { (years) }\end{array}$ & Type of trauma & Psychological measure \\
\hline Amir et al., 199825 & 15 & $0 / 15$ & $28 \pm 8$ & Terrorist atack & IES, PDS, SCL \\
\hline Sijbrandij et al., 20067 & 236 & $121 / 115$ & $41.7 \pm 12.3$ & Assault, accidents & HADS, PSS \\
\hline Bisson et al., $2004^{9}$ & 152 & $65 / 87$ & Not informed & Physical injury & CAPS, HADS, IES \\
\hline Brom et al., 199334 & 151 & $89 / 62$ & $39 \pm 17$ & Traffic accident & IES \\
\hline Bryant et al., 199910 & 45 & $22 / 23$ & $32.5 \pm 10.9$ & Civilian trauma survivors & BDI, Event scale, STAI \\
\hline Bryant et al., 200930 & 156 & $101 / 54$ & $37.17 \pm 13.27$ & Traumatic injury & CAPS, MINI \\
\hline Deahl et al., 200011 & 106 & $106 / 0$ & 24 & War & CAPS, CAGE, HADS, PTSS, SCL \\
\hline Delahanty et al., 201312 & 64 & $42 / 32$ & $30.6 \pm 10.7$ & Traumatic injury & CAPS, CES-D, PDI, PDEQ, SF-36 \\
\hline Gamble et al., 200513 & 103 & $0 / 103$ & $28 \pm 6.04$ & Experienced a distressing or traumatic birth & DASS, EPDS, MINI \\
\hline Gidron et al., $2001^{14}$ & 17 & 09/08 & 36.2 & Motor vehicle accidents & CAPS, SCl \\
\hline Gidron et al., 200729 & 34 & $18 / 16$ & $28.3 \pm 10.0$ & Traffic accident & PTDS \\
\hline Holmes et al., 200735 & 90 & $63 / 27$ & $39.9 \pm 15.8$ & Physical trauma & AUDIT, HADS, IPC, PCL \\
\hline Marchand et al., 200626 & 75 & $36 / 39$ & 22.4 years \pm 7.3 & Armed robbery & CAPS, IES \\
\hline Matsuoka et al., $2015^{46}$ & 110 & $90 / 20$ & $38.1 \pm 13.5$ & Accident-injured & CD-RISC, CAPS, HADS, IES-R, MADRS \\
\hline Miller et al., 201515 & 164 & $0 / 164$ & $26.62 \pm 9.32$ & Sexual assault & BDI, BAI, PSS \\
\hline Mouthaan et al., 201324 & 300 & $89 / 62$ & $43.8 \pm 15.9$ & Traumatic injury & CAPS, GCS, HADS, ISS \\
\hline Pitman et al., 200231 & 41 & $20 / 21$ & $34.3 \pm 11.1$ & Psychologically traumatic event & CAPS \\
\hline Price et al., 201427 & 137 & $47 / 89$ & $31.4 \pm 11.65$ & Criterion A trauma according to the DSM-IV & CTO, ISRC, PSS, STI \\
\hline Resnick et al., 200716 & 140 & $0 / 140$ & $25.82 \pm 10.32$ & Sexual assault & BDI, BAI, PSS \\
\hline Rothbaum et al., $2008^{17}$ & 145 & $88 / 57$ & $39.4 \pm 16$ & $\begin{array}{l}\text { Motor vehicle collision, unspecified trauma, } \\
\text { physical assault }\end{array}$ & CGI, BDI, STAI \\
\hline Rothbaum et al., $2012^{18}$ & 137 & $69 / 68$ & $\begin{array}{l}30.17 \pm 12.08 / \\
32.78 \pm 11.12\end{array}$ & $\begin{array}{c}\text { Sexual assault, physical assault and } \\
\text { transportation }\end{array}$ & BDI, ISRC, CTO, PTSR, PSS \\
\hline Rothbaum et al., 201419 & 65 & $25 / 40$ & $33 \pm 11.6$ & Rape, nonsexual assault, vehicle accident & CTQ, PSS, PDS \\
\hline Ryding et al., 200432 & 50 & $0 / 50$ & 30 & Emergency cesarean section & DEQ, IES \\
\hline Scholes et al. 200720 & 347 & $191 / 151$ & $38.55 \pm 14.97$ & Patients attending accident/emergency & ASDS, HADS, PDS \\
\hline Suliman et al. $2015^{8}$ & 29 & $19 / 10$ & $29.52 \pm 8.17$ & $\begin{array}{l}\text { Vehicle collision or other accident, physical or } \\
\text { sexual assault }\end{array}$ & $\begin{array}{l}\text { ASD, MADRS, CAPS, CGI-S, CGI-I, } \\
\text { MADRS, SDS, PDS, VAS-D, VAS-A }\end{array}$ \\
\hline Stein et al., 200721 & 48 & Not stated & $29.4 \pm 10.10$ & Physical trauma & CIDI, CES-D, PCL-C \\
\hline Vaiva et al., $2003^{22}$ & 20 & $11 / 08$ & $23.90 \pm 10.59$ & Motor vehicle accidents, physical assault & MINI, PDI, PDS, TS, TO \\
\hline Zatzick et al., 200136 & 152 & Not stated & $38 \pm 14.7$ & Physical injury & PCL-C \\
\hline Zoellner et al., 201123 & 90 & $0 / 90$ & 33.7 & Assault survivors & BDI, PSS, PBRS \\
\hline
\end{tabular}

AIS: Abbreviated Injury Scale; BDI: Beck Depression Inventory; CAPS: Clinician Administered PTSD Scale; CGI: Clinical Global Improvement Scale; CIDI: Comprehensive International Diagnostic Interview; CTQ: Childhood Trauma Questionnaire; DASS: Depression Anxiety and Stress Scale; DSM-IV: Diagnostic and Statistical Manual of Mental Disorders; EPDS: Edinburgh Postnatal Depression Scale; HADS: Hospital Anxiety and Depression Scale; IES: Impact of Event Scale; IPC: interpersonal counseling; ISRC: Immediate Stress Reaction Checklist; MINI: Mini International Neuropsychiatric Interview; MSS: Maternity Social Support Scale; PCL: post-trauma stress disorder checklist; PDS: PTSD Diagnostic Scale; PDI: Peritraumatic Distress Inventory; PDEQ: Peritraumatic Dissociative Experiences Questionnaire; PSS: PTSD Symptom Scale-l; STAI: State-Trait Anxiety Inventory; SDS: Sheehan Disability Scale; STI: Standardized Trauma Interview; TS: Trauma Score; TO: Treatment Outcome; TSI: Trauma Symptom Inventory. 
Table 2. Methodological aspects and results of the articles included in the review

\begin{tabular}{|c|c|c|c|c|c|}
\hline Reference & Type of intervention & Time up to intervention & Follow-up & Results & $\begin{array}{l}\text { Result } \\
+ \text { or - }\end{array}$ \\
\hline \multicolumn{6}{|l|}{ Psychological } \\
\hline Amir et al., 199825 & Debriefing (6 sessions) & 2 days after trauma & 2 and 6 months & $27 \%$ diagnosed with PTSD & $+/-$ \\
\hline Sijbrandij et al., 20067 & Debriefing (1 session) & 15 days after trauma & $\begin{array}{l}2 \text { and } 6 \text { weeks and } \\
6 \text { months }\end{array}$ & $\begin{array}{l}\text { Symptom decrease in all } 3 \text { groups/ } \\
\text { emotional debriefing had an adverse effect } \\
\text { in participants with early hyperarousal } \\
\text { symptoms }\end{array}$ & + \\
\hline Bisson et al., 20049 & CBT (4 sessions) & 1-3 weeks post-injury & 3 and 13 months & IES reduced in the intervention group & + \\
\hline Brom et al., $1993^{34}$ & Preventive counseling program & Not informed & 1 and 6 months & $10 \%$ of the victims suffered from PTSD & - \\
\hline Bryant et al., 199910 & $\begin{array}{l}5 \text { sessions of (1) prolonged } \\
\text { exposure; (2) a combination of } \\
\text { prolonged exposure; and ( } 3 \text { ) } \\
\text { anxiety management supportive } \\
\text { counseling }\end{array}$ & 2 weeks & 6 months & $\begin{array}{l}\text { Fewer patients with prolonged exposure/ } \\
\text { prolonged exposure + anxiety management } \\
\text { met criteria for PTSD after treatment }\end{array}$ & + \\
\hline Deahl et al., 200011 & $\begin{array}{l}\text { Operational Stress Training } \\
\text { Package pre and post trauma }\end{array}$ & Not informed & 3 and 6 months and 1 year & $\begin{array}{l}\text { CAGE scores decreased in the debriefed } \\
\text { group by the end of the follow-up }\end{array}$ & + \\
\hline Gamble et al., $2005^{13}$ & $\begin{array}{l}\text { Counseling } 72 \mathrm{~h} \text { after birth and } \\
\text { at } 4 \text { to } 6 \text { weeks postpartum }\end{array}$ & $\begin{array}{l}72 \text { hours and } 4 / 6 \text { weeks } \\
\text { after birth }\end{array}$ & 3 months & $\begin{array}{l}\text { Decreased trauma symptoms, low relative } \\
\text { risk of depression, low relative risk of } \\
\text { stress, and low feelings of self-blame }\end{array}$ & + \\
\hline Gidron et al., $20011^{4}$ & Memory structuring intervention & 24 hours after trauma & 3 months & $\begin{array}{l}\text { Patients reported significantly less } \\
\text { frequent intrusive, arousal, and total PTSD } \\
\text { symptoms than controls }\end{array}$ & + \\
\hline Gidron et al., 200729 & $\begin{array}{l}\text { Memory structuring intervention } \\
\text { or supportive listening }\end{array}$ & $\begin{array}{l}24 \text { to } 48 \text { hours after } \\
\text { trauma }\end{array}$ & 3 months & No overall group differences were found & - \\
\hline Holmes et al., 200735 & $\begin{array}{l}\text { Interpersonal counseling } \\
\text { (6 sessions) }\end{array}$ & $\begin{array}{l}\text { Within } 2 \text { weeks after } \\
\text { trauma }\end{array}$ & 3 and 6 months & $\begin{array}{l}\text { Level of depressive, anxiety and post- } \\
\text { traumatic symptoms and prevalence of } \\
\text { psychiatric disorders did not differ }\end{array}$ & - \\
\hline Marchand et al., 200626 & $\begin{array}{l}\text { Critical Incident Stress } \\
\text { Debriefing (2 sessions) }\end{array}$ & 2 to 22 days after trauma & 40 and 110 days & $\begin{array}{l}\text { No differences between the CISD-A and the } \\
\text { control group in preventing PTSD }\end{array}$ & + \\
\hline Miller et al., 201515 & Video intervention & 72 hours after trauma & 2 weeks and 2 months & $\begin{array}{l}\text { Significantly fewer anxiety symptoms at the } \\
\text { follow-up assessments }\end{array}$ & + \\
\hline Mouthaan et al., 201324 & $\begin{array}{l}\text { Self-guided Internet-based } \\
\text { intervention based on CBT }\end{array}$ & 1 week after trauma & $1,3,6$ and 12 months & $\begin{array}{l}\text { No support for the efficacy of the Trauma } \\
\text { TIPS in the prevention of PTSD symptoms }\end{array}$ & - \\
\hline Price et al., 201427 & $\begin{array}{l}\text { Prolonged exposure intervention } \\
\text { or assessment-only condition } \\
\text { (3 sessions) }\end{array}$ & $\begin{array}{l}\text { In the emergency } \\
\text { department after the } \\
\text { patient was medically } \\
\text { stable }\end{array}$ & $\begin{array}{l}4 \text { and } 12 \text { weeks } \\
\text { posttrauma }\end{array}$ & $\begin{array}{l}\text { Dissociation at the time at which treatment } \\
\text { starts may indicate poorer response to } \\
\text { early intervention. Those with reduced } \\
\text { dissociation at the start of treatment } \\
\text { benefited most from early treatment }\end{array}$ & $+/-$ \\
\hline Resnick et al., 200716 & Video intervention & 72 hours after trauma & 6 weeks and 6 months & $\begin{array}{l}\text { Time 1: intervention associated with lower } \\
\text { PTSD and depression scores among women } \\
\text { with a prior rape history relative to women } \\
\text { in the standard care condition. Time 2: } \\
\text { depression scores were lower among those } \\
\text { with a prior rape history who were in the } \\
\text { video intervention }\end{array}$ & + \\
\hline Rothbaum et al., $2008^{17}$ & $\begin{array}{l}\text { Individualized exposure-based } \\
\text { therapy (CBT, } 1 \text { session) }\end{array}$ & 24 hours after trauma & 1 week & $\begin{array}{l}\text { Patients: slightly decrease in depression } \\
\text { and lower scores in clinician-rated global } \\
\text { severity of symptoms than patients in the } \\
\text { assessment-condition }\end{array}$ & + \\
\hline Rothbaum et al., $2012^{18}$ & $\begin{array}{l}\text { Early intervention CBT } \\
\text { (3 sessions) }\end{array}$ & 12 hours after trauma & 1 and 3 months & $\begin{array}{l}\text { Intervention participants reported } \\
\text { significantly lower PTSR than the } \\
\text { assessment group at } 4 \text { and } 12 \text { weeks post } \\
\text { injury }\end{array}$ & + \\
\hline Rothbaum et al., 201419 & $\begin{array}{l}\text { Exposure intervention } \\
\text { ( } 3 \text { sessions) }\end{array}$ & $\begin{array}{l}\text { Emergency department } \\
\text { shortly after trauma }\end{array}$ & 4 and 12 weeks & $\begin{array}{l}\text { Combined genetic variants may serve to } \\
\text { predict those most at risk for developing } \\
\text { PTSD following trauma. Psychotherapeutic } \\
\text { intervention may mitigate this risk }\end{array}$ & + \\
\hline Ryding et al., 200432 & $\begin{array}{l}\text { Counseling ( } 2 \text { sessions) } \\
\text { conducted about } 2 \text { months } \\
\text { postpartum }\end{array}$ & $1 / 2$ month after trauma & 6 months & $\begin{array}{l}\text { No difference between the groups was } \\
\text { found }\end{array}$ & - \\
\hline Scholes et al., 200720 & Self-help information & $\begin{array}{l}\text { Within } 1 \text { month after } \\
\text { trauma }\end{array}$ & 3 months & No group diferences & - \\
\hline
\end{tabular}




\begin{tabular}{|c|c|c|c|c|c|}
\hline Reference & Type of intervention & Time up to intervention & Follow-up & Results & $\begin{array}{l}\text { Result } \\
+ \text { or - }\end{array}$ \\
\hline Zatzick et al., 200136 & $\begin{array}{l}\text { Collaborative care intervention } \\
\text { (4 months) }\end{array}$ & Newly admitted patients & 1,4 months & $\begin{array}{l}\text { First month: decreased PTSD and } \\
\text { depressive symptoms/4 months: no } \\
\text { significant improvements in PTSD and } \\
\text { depressive symptoms }\end{array}$ & $+/-$ \\
\hline Zoellner et al., 201123 & $\begin{array}{l}\text { Brief cognitive } \\
\text { behavioral intervention } \\
\text { (4 weeks) }\end{array}$ & 20 days after trauma & $2,3,6,9$ and 12 months & $\begin{array}{l}\text { Brief cognitive-behavioral intervention } \\
\text { caused changes in perceptions of self and } \\
\text { changes in trauma-related symptom }\end{array}$ & + \\
\hline \multicolumn{6}{|l|}{ Pharmachological } \\
\hline Bryant et al., 200930 & Single dose of morphine & $\begin{array}{l}\text { Between } 48 \text { hours and } 7 \\
\text { days after trauma }\end{array}$ & 3 months & $\begin{array}{l}\text { 14\% met criteria for PTSD at } 3 \text { months. } \\
\text { Patients who developed PTSD received } \\
\text { less morphine than those without PTSD. } \\
\text { Morphine administered in the initial } 48 \\
\text { hours was apparently more protective than } \\
\text { the dose administered over the initial week }\end{array}$ & + \\
\hline Delahanty et al., 201312 & $\begin{array}{l}10 \text { days of hydrocortisone } \\
(20 \mathrm{mg}) \text { or placebo }\end{array}$ & 12 hours after trauma & 1 and 3 months & $\begin{array}{l}\text { Hydrocortisone recipients reported fewer } \\
\text { PTSD and depression symptoms than } \\
\text { placebo recipients }\end{array}$ & + \\
\hline Matsuoka et al. 201546 & $\begin{array}{l}1,470 \mathrm{mg} / \mathrm{d} \text { of DHA plus } \\
147 \mathrm{mg} / \mathrm{d} \text { of eicosapentaenoic } \\
\text { acid or placebo for } 12 \text { weeks }\end{array}$ & 3 days after trauma & 3 months & $\begin{array}{l}11.1 \% \text { of the DHA group and } 5.5 \% \text { of the } \\
\text { placebo group developed PTSD }\end{array}$ & - \\
\hline Pitman et al., $2002^{31}$ & $\begin{array}{l}10 \text { days of propranolol } 40 \mathrm{mg} \text { or } \\
\text { placebo ( } 4 \text { times daily) }\end{array}$ & 6 hours after trauma & 1 and 3 months & $\begin{array}{l}\text { Non significant trend for propranolol } \\
\text { group CAPS scores did not differ in the } \\
\text { propranolol and placebo groups }\end{array}$ & - \\
\hline Stein et al., 200721 & $\begin{array}{l}14 \text { days: propranolol, anxiolytic } \\
\text { anticonvulsant gabapentin or } \\
\text { placebo }\end{array}$ & 48 hours after trauma & 1,4 and 8 months & $\begin{array}{l}\text { None of the study drugs showed a } \\
\text { significant benefit over placebo on } \\
\text { depressive or post-traumatic stress } \\
\text { symptoms }\end{array}$ & - \\
\hline Suliman et al., $2015^{8}$ & $\begin{array}{l}10-20 \mathrm{mg} \text { of escitalopram or } \\
\text { placebo daily for } 24 \text { weeks }\end{array}$ & $\begin{array}{l}\text { Within } 1 \text { month after } \\
\text { trauma }\end{array}$ & $\begin{array}{l}\text { Weeks } 0,4,12,24,32 \text {, } \\
40,48 \text { and } 56\end{array}$ & $\begin{array}{l}\text { Significant reduction in CAPS scores } \\
\text { over the course of treatment in both the } \\
\text { escitalopram and placebo groups }\end{array}$ & - \\
\hline Vaiva et al., 200322 & $\begin{array}{l}3 \text { times daily for } 7 \text { days: } 40 \mathrm{mg} \\
\text { of propranolol }\end{array}$ & $2-20$ hours after trauma & 2 months & $\begin{array}{l}\text { PTSD rates were higher in the group that } \\
\text { refused propranolol when compared to the } \\
\text { group who received propranolol }\end{array}$ & + \\
\hline
\end{tabular}

CBT: Cognitive Behavior Therapy; CAPS: Clinician Administered PTSD Scale; CISD-A: Critical Incident Stress Debriefing; DHA: docosahexaenoic acid; PTSR: posttraumatic stress reactions; PTSD: post-traumatic stress disorder; + positive result; - negative result; +/- indefinite r.

\section{Cognitive behavioral therapy (CBT)}

Four of the six studies that used CBT or related techniques reported results compatible with reduced occurrence of PTSD or PTSDrelated symptoms in groups who underwent interventions in relation to control groups ${ }^{9,17-19}$. In the study by Mouthaan et al. ${ }^{24}$, which did not report reductions in the occurrence of PTSD, the authors discuss the fact that one-fifth of the volunteers failed to adhere to the intervention program. Another possible explanation for these results could be related to the low level of PTSD symptoms in the sample, which may have hampered the detection of improvements in the group that received the intervention.

In respect to the methodological aspects of these studies, the duration of treatment varied between 1-12 weeks and follow-up assessments were made in all the investigations. Regarding the type of intervention, there was no homogeneity in respect to the techniques described in the articles. Despite the positive results, additional studies involving larger and more homogeneous samples and longer follow-up periods are desirable to clarify the effects of such interventions.

\section{Debriefing}

Four articles described the use of interventions based on a techniques know as debriefing $7,11,25,26$. Debriefing involves different forms of brief counseling and is aimed at allowing victims of psychological trauma to process their experiences cognitively and emotionally. The technique is generally applied hours after the occurrence of a traumatic event ${ }^{28}$. The results obtained with this technique are convergent in respect to the poor efficacy of the method in the prevention of PTSD and, in some cases, there were reports of symptom worsening. The authors of the studies that used this technique discuss that the poor effectiveness of the interventions performed may be due to the long interval between the occurrence of the traumatic event and the beginning of debriefing 26 .

\section{Other types of psychological intervention}

Thirteen studies used different types of intervention including, for example, video-based interventions, counseling, and self help programs (e.g., psychoeducational and motivational techniques). Six of these studies suggest that the interventions resulted in a decrease in PTSD symptoms when compared to groups that did not receive the intervention. Despite these results, in one of the studies participants received training for stress management before the occurrence of the traumatic event (war combat), as well as psychological interventions after the trauma. Therefore, it is still a matter of debate whether the results obtained stem from the primary or the secondary intervention, that is, if they come from the intervention that preceded or the one that followed the trauma ${ }^{11}$.

In respect to the studies that found no significant changes in PTSD and PTSD-related symptoms, some contradictions should be mentioned. For example, a study by Gidron ${ }^{29}$ reported that women participating in a given intervention had a lower frequency of PTSD 
symptoms than men taking part in the same intervention ${ }^{29}$, which contrasts with previous results from the same group ${ }^{14}$.

\section{Pharmacological interventions}

As shown in Table 2, drugs used in the selected studies included propranolol, escitalopram, docosahexaenoic and eicosapentaenoic acid, hydrocortisone, and morphine. Among the five trials using pharmacological interventions, only one used a single dose of the test medication ${ }^{30}$. On average, test medications were administered for seven days in the remaining studies.

Two articles reported results compatible with a lower occurrence of PTSD and related symptoms ${ }^{12,22}$. These results were based mainly on scales applied after the intervention and at follow-up assessments.

In the studies that found no statistically significant effects of pharmacological interventions in the prevention of PTSD, the authors described variables that may have interfered in their results, such as poor adherence to treatment, and suggest that it may be preferable to recruit individuals at increased risk of developing PTSD, such as individuals with high stress levels ${ }^{21}$.

The article by Bryant et al. ${ }^{30}$ reported that, although no significant results were found in terms of PTSD symptoms, the acute administration of morphine had a protective effect related to the severity of PTSD. Another study reported that, despite their weak results, propranolol may be useful in the prevention of PTSD because the results of psychophysiological tests suggest that the drug reduces the arousal elicited by exposure to stimuli resembling the traumatic event ${ }^{31}$.

In addition to the results described above, methodological aspects including sample size, gender and age of participants, type of trauma, assessment scales, randomization procedures, intervention starting time, and follow-up duration also deserve attention, as they can have a direct impact on the results obtained.

\section{Other relevant aspects}

In respect to the sample size, we highlight the discrepancy in the number of participants across the studies. Some authors have underscored the need for further investigations involving larger samples in order to confirm the data obtained to date $14,22,25$.

Regarding the gender of participants, two of the articles reviewed had discrepancies in the number of female and male participants ${ }^{20,39}$. Both studies included a higher number of men in the groups of patients undergoing the intervention compared to the other groups. It should also be noted that, in some studies, samples were formed exclusively by women ${ }^{13,16,17,23,25,32}$ or men ${ }^{11}$. Although the authors make no mention to the discrepancies in the numbers of male and female participants, evidence points to a higher vulnerability to PTSD in females ${ }^{33}$. Therefore, studies with unbalanced gender distributions may not be as representative as studies with gender-balanced samples in what concerns the prevalence of the disorder. This can be, however, a limitation that is difficult to overcome in populations that are more vulnerable to certain types of trauma and with a high predominance of one gender, as in the case of soldiers (mainly men) or victims of sexual abuse (mainly women).

Only one of the articles reviewed did not inform the mean age of participants ${ }^{8}$. This is highly relevant because, although the onset of PTSD may occur at any age, it is more common in young adults since they are more prone to have the type of experiences that trigger the disorder ${ }^{33}$. Still in respect to the age of study participants, there was less homogeneity in the data presented by some authors , $^{7,1734-36}$. These articles do not discuss the age discrepancies in their samples, as well as the possible influence of this factor on their results.

From the 29 articles reviewed, four had no uniform samples in terms of the type of trauma experienced, that is, these studies assessed more than one type of trauma ${ }^{17,18,22,28}$. There is evidence in the literature of correlations between the type of trauma experienced and gender-related vulnerability ${ }^{37}$. In this sense, variations in the types of trauma assessed in a same study can be seen as a limitation that hinders the reproducibility of its results.

The most frequently used scale in the studies included in this review was the Clinician Administered PTSD Scale (CAPS 38 ), designed to assess PTSD symptoms. Despite that, there was no standard in what concerns the instruments used in the articles reviewed. In general, the studies included scales to assess symptoms of depression and anxiety. The lack of homogeneity in the types of instruments used in the studies also hampers the comparison of results available to date, as well as the generalization of findings.

The randomization and blinding strategies used in the trials were also examined in this review. Only one of the articles included informed that the study sample had not been randomized ${ }^{22}$. Four of the studies were described by their authors as single-blind ${ }^{13,14,18,22}$, five did not include information about whether they were doubleblind trials or not $7,1827,32,34$, and one informed that the trial was "not double-blind". In respect to the study design, only two articles did not describe the inclusion of comparison groups 25,30 . The remaining articles included one or more comparison groups. Still regarding the study design, the trial by Bryant et al. ${ }^{30}$ used an observational design, assessing the use of morphine after the trauma and the development of PTSD-related symptoms in the follow-up.

The time between the occurrence of the trauma and the beginning of the intervention varied greatly across studies, from 6 hours ${ }^{31}$ to 10 weeks 9 . It has been argued that the shorter the interval between the traumatic event and the beginning of the intervention, the more likely is the blockade of the consolidation of aversive memories ${ }^{17}$ with a consequent reduction in the possible negative emotional consequences of the trauma. Regarding follow-up assessments, all the studies reviewed included this type of analysis; however, the frequency and the interval between assessments varied.

Some limitations related to follow-up assessments were pointed in the studies reviewed, such as excessively short intervals between assessments ${ }^{17}$ and poor treatment adherence by participants during long follow-up periods ${ }^{24}$. Finally, one limitation described in some studies refers to the intrinsic difficulties of proving the efficacy of early interventions, since a significant part of volunteers may not be vulnerable to the development of PTSD. Future research should seek to determine reliable criteria for the identification of trauma victims at risk of developing PTSD, which would allow improved assessments of the interventions performed. As an example, psychological and biological factors are known to influence the vulnerability to PTSD, including internalizing behavioral problems, psychiatric comorbidities, alterations in the hypothalamic-pituitary adrenal axis, brain abnormalities, and genetic factors ${ }^{39,40}$.

\section{Conclusion}

The main difficulty in the analysis of the 29 articles included in this review rose from the significant methodological variations across the studies, as discussed above. In general terms, we conclude that studies using psychological interventions lack homogeneity in respect to the type of intervention and measures used to assess intervention outcomes. Pharmacological trials were less frequent in the area of PTSD prevention and should have their findings replicated, in addition to expanding the range of drugs tested. Possible investigation targets for future research include cannabinoid compounds, and especially cannabidiol (CBD), since this compound seems to play an important role in the blockade of the reconsolidation of aversive memories ${ }^{41}$. In addition, preclinical studies provide support for the test of oxytocin as a promising strategy in the prevention of PTSD-like manifestations ${ }^{42}$.

Despite the methodological issues described above, the studies reviewed further our understanding about PTSD and interventions aimed at preventing the disorder or minimizing post-trauma symptoms ${ }^{43-48}$. Importantly, many of the articles reviewed suggest that pharmacological and psychological interventions are effective in this regard. However, we were unable to find studies that combined pharmacological and psychological interventions. Since 
this association has proved useful in the management of other psychiatric conditions (e.g., OCD, panic disorder, depression, alcohol dependence), the use of combined interventions in post-trauma volunteers could bring important contributions to the field.

\section{Conflict of interest}

The authors have no conflict of interest related to the topic of this article. The funding agency had no role in the study design or in the decision to submit the paper for publication.

\section{Acknowledgments}

JAC and AWZ are recipients of fellowship awards from Conselho Nacional de Desenvolvimento Científico e Tecnológico (CNPq, Brazil). The present study is supported by a CNPq Grant (CNPq/ MS/SCTIE/DECIT No 26/2014 - Pesquisas sobre Distúrbios Neuropsiquiátricos; 466805/2014-4). RM-S was also supported by the Generalitat de Cataluny/Support a les activitats del Grups de Recerca): SGR2014/1411.

\section{References}

1. Silva TL, Donat JC, Gauer G, Kristensen CH. Posttraumatic growth measures: translation and adaptation of three self-report instruments to Brazilian Portuguese. Arch Clin Psychiatry. 2016;43(3):47-50.

2. Kessler RC, Berglund P, Delmer O. Lifetime prevalence and age-of-onset distributions of DSM-IV disorders in the National Comorbidity Survey Replication. Arch Gen Psychiatry. 2005;62(6):593-602.

3. Kearns M, Ressler K, Zatzick D, Rothbaum B. Early interventions for PTSD: a review. Depress Anxiety. 2012;29(10):833-42.

4. World Health Organization. 2004. Prevention of Mental Disorders. Available from: <http://www.who.int/en/>. Accessed on: Dez 1. 2016.

5. Rosenthal R. Meta-analytic procedures for social research (rev. ed.). 1991. Newbury Park, CA: Sage.

6. Marsac ML, Kassam-Adams N, Delahanty DL, Widaman KF, Barakat LP. Posttraumatic stress following acute medical trauma in children: a proposed model of bio-psycho-social processes during the peri-trauma period. Clin Child Fam Psychol Rev. 2014;17(4):399-411.

7. Sijbrandij M, Olff M, Reitsma JB. Emotional or educational debriefing after psychological trauma: randomised controlled trial. Br J Psychiatry. 2006;189(2):150-5.

8. Suliman S, Seedat S, Pingo J, Sutherland T, Zohar J, Stein DJ. Escitalopram in the prevention of posttraumatic stress disorder: a pilot randomized controlled trial. BMC Psychiatry. 2015;19:15-24.

9. Bisson J, Shepherd J, Joy D. Early cognitive-behavioural therapy for posttraumatic stress symptoms after physical injury: Randomised controlled trial. Br J Psychiatry. 2004;184:63-9.

10. Bryant R, Sackville T, Dang S, Moulds M, Guthrie S. Treating acute stress disorder: an evaluation of cognitive behavior therapy and supportive counseling techniques. Am J Psychiatry. 1999;156(11):1780-6.

11. Deahl M, Srinivasan M, Jones N, Thomas J, Neblett C, Jolly A. Preventing psychological trauma in soldiers: the role of operational stress training and psychological debriefing. Br J Med Psychol. 2000;73:77-85.

12. Delahanty D, Gabert-Quillen C, Ostrowski S. The efficacy of initial hydrocortisone administration at preventing posttraumatic distress in adult trauma patients: a randomized trial. CNS Spectrums. 2013;18(2):103-11.

13. Gamble J, Creedy D, Moyle W, Webster J, McAllister M, Dickson P. Effectiveness of a counseling intervention after a traumatic childbirth: a randomized controlled trial. B Psych (Hons). 2005;32:41.

14. Gidron Y, Gal R, Freedman S. Translating research findings to PTSD prevention: results of a randomized-controlled pilot study. J Trauma Stress. 2001;14(4):773-80.

15. Miller KE, Cranston CC, Davis JL, Newman E, Resnick H. Psychological Outcomes After a Sexual Assault Video Intervention: A Randomized Trial. J Forensic Nurs. 2015;11(3):129-36.

16. Resnick H, Acierno R, Waldrop A. Randomized controlled evaluation of an early intervention to prevent post-rape psychopathology. Behav Res Ther. 2007;45:2432-7.

17. Rothbaum BO, Houry D, Heekin M, Leiner A, Daugherty J, Smith S, et al. Pilot study of an exposure-based intervention in the ED designed to prevent posttraumatic stress disorder. Am J Emerg Med. 2008;26(3):326-30.
18. Rothbaum BO, Kearns MC, Price M, Malcoun E, Davis M, Ressler KJ, et al. Early intervention may prevent the development of posttraumatic stress disorder: a randomized pilot civilian study with modified prolonged exposure. Biol Psychiatry. 2012;72(11):957-63.

19. Rothbaum B, Kearns M, Reiser E, Davis J, Kerley K, Rothbaum A, et al. Early Intervention Following Trauma May Mitigate Genetic Risk for PTSD in Civilians: A Pilot Prospective Emergency Department Study. J Clin Psychiatry. 2014;75(12):1380-7.

20. Scholes C, Turpin G, Mason S. A randomised controlled trial to assess the effectiveness of providing self-help information to people with symptoms of acute stress disorder following a traumatic injury. Behav Res Ther. 2007;45(11):2527-36.

21. Stein M, Kerridge C, Dimsdale J. Pharmacotherapy to prevent PTSD Results from a randomized controlled proof-of-concept trial in physically injured patients. J Trauma Stress. 2007;20(6):923-32.

22. Vaiva G, Ducrocq F, Jezequel K. Immediate treatment with propranolol decreases posttraumatic stress disorder two months after trauma. Biol Psychiatry. 2003;54:947-9.

23. Zoellner LA, Feeny NC, Eftekhari A, Foa EB. Changes in negative beliefs following three brief programs for facilitating recovery after assault. Anxiety. 2011;28(7):532-40.

24. Mouthaan J, Sijbrandij M, de Vries GJ, Reitsma JB, van de Schoot $\mathrm{R}$, Goslings JC, et al. Internet-based early intervention to prevent posttraumatic stress disorder in injury patients: Randomized controlled trial. J Med Internet Res. 2013;15(8):e165.

25. Amir M, Weil G, Kaplan Z, Tocker T, Witztum E. Debriefing with brief group psychotherapy in a homogenous group of non-injured victims of a terrorist attack: a prospective study. Acta Psychiatr Scand. 1998;98(3):237-42.

26. Marchand A, Guay S, Boyer R, Iucci S, Martin A, Hilaire M A Randomized Controlled Trial of an Adapted Form of Individual Critical Incident Stress Debriefing for Victims of an Armed Robbery. Brief Treat Crisis Interv. 2006;6(2):123.

27. Price M, Kearns M, Houry D, Rothbaum B. Emergency department predictors of posttraumatic stress reduction for trauma-exposed individuals with and without an early intervention. J Consult Clin Psychol. 2014;82(2):336-41.

28. Rachman S. Emotional processing. Behav Res Ther. 1980;18(1):51-60.

29. Gidron Y, Gal R, Givati G, Lauden A, Snir Y, Benjamin J. Interactive effects of memory structuring and gender in preventing posttraumatic stress symptoms. J Nerv Ment Dis. 2007;195(2):179-82.

30. Bryant R, Creamer M, O'Donnell M, Silovre D, McFarlane A. A study of the protective function of acute morphine administration on subsequent posttraumatic stress disorder. Biol Psychiatry. 2009;65(5):438-40.

31. Pitman RK, Sanders KM, Zusman RM, Healy AR, Cheema F, Lasko NB, et al. Pilot study of secondary prevention of posttraumatic stress disorder with propranolol. Biol Psychiatry. 2002;51(2):189-92.

32. Ryding E, Wiren E, Johansson G, Ceder G, Dahlstrom A. Group counseling for mothers after emergency cesarean section: a randomized controlled trial of intervention. Birth. 2004;31(4):247-53.

33. Javidi H, Yadollahie M. Post-traumatic Stress Disorder. Theijoen. 2012;3(1):1-8.

34. Brom D, Kleber RJ, Hofman M. Victims of traffic accidents: Incidence and prevention of post-traumatic stress disorder. J Clin Psychol. 1993;49(2):131-40.

35. Holmes A, Hodgins G, Adey S, Menzel S, Danne P, Kossmann T, et al. Trial of interpersonal counselling after major physical trauma. Aust $\mathrm{N}$ Z J Psychiatry. 2007;41(11):926-33.

36. Zatzick D, Roy-Byrne P, Russo J, Rivara F, Koike A, Jurkovich G, et al. Collaborative interventions for physically injured trauma survivors: a pilot randomized effectiveness trial. Gen Hosp Psychiatry. 2001;23(3):114-23.

37. Punamäki RL, Komproe IH, Qouta S, Elmasri M, de Jong JT. The role of peritraumatic dissociation and gender in the association between trauma and mental health in a Palestinian community sample. Am J Psychiatry 2005; 162:545-51.

38. Bitencourt R, Pamplona F, Takahashi R. Facilitation of contextual fear memory extinction and anti-anxiogenic effects of AM404 and cannabidiol in conditioned rats. Eur Neuropsychopharmacol. 2008;18(12):849-59. 
39. Leen-Feldner EW, Feldner MT, Knapp A. Offspring psychological and biological correlates of parental posttraumatic stress: review of the literature and research agenda. Clin Psychol Rev. 2013;33(8):1106-33.

40. Yahyavi ST, Zarghami M, Marwah U. A review on the evidence of transgenerational transmission of posttraumatic stress disorder vulnerability. Rev Bras Psiquiatr. 2014;36(1):89-94.

41. Marsicano G, Wotjak, CT, Azad SC, Bisogno T, Rammes G, Cascio MG, et al. The endogenous cannabinoid system controls extinction of aversive memories. Nature. 2002;418:530-4.

42. Frijling JL, van Zuiden M, Koch SB, Nawijn L, Goslings JC, Luitse JS, et al. Efficacy of oxytocin administration early after psychotrauma in preventing the development of PTSD: study protocol of a randomized controlled trial. BMC Psychiatry. 2014;14:92.

43. Holbrook TL, Galarneau MR, Dye JL, Quinn K, Dougherty AL. Morphine use after combat injury in Iraq and post-traumatic stress disorder. N Engl J Med. 2010;362(2):110-7.
44. Kimbrel NA, Meyer EC, Beckham A. Clinician's perspective on memory reconsolidation as the primary basis for psychotherapeutic change in posttraumatic stress disorder (PTSD). Behav Brain Sci. 2015;38(8):1-3.

45. Matsuoka Y, Nishi D, Yonemoto N, Hamazaki K, Matsumura K, Noguchi $\mathrm{H}$, et al. Tachikawa project for prevention of posttraumatic stress disorder with polyunsaturated fatty acid (TPOP): study protocol for a randomized controlled trial. BMC Psychiatry. 2013;13:8.

46. Matsuoka Y, Nishi D, Hamazaki K, Yonemoto N, Matsumura K, Noguchi $\mathrm{H}$, et al. Docosahexaenoic acid for selective prevention of posttraumatic stress disorder among severely injured patients: a randomized, placebocontrolled trial. J Clin Psychiatry. 2015;76(8):1015-22.

47. Mouthaan J, Sijbrandij M, Reitsma JB, Gersons BP, Olff M. Internet-based prevention of posttraumatic stress symptoms in injured trauma patients: design of a randomized controlled trial. Eur J Psychotraumatol. 2011;2.

48. Donadon MF, Osorio FL. Early emotional trauma in alcohol-dependent men: prevalence, associations and predictive value. Arch Clin Psychiatry. 2016;43(3):41-6. 